\title{
A PRESENÇA DO BRASIL E DE SUA LITERATURA NA REVISTA PORTUGUESA A MADRUGADA (1894-1896)
}

\author{
PÓVOAS, Mauro Nicola ${ }^{1}$
}

RESUMO: O artigo tem por objetivo analisar alguns aspectos de A Madrugada - Revista Noticiosa, Crítica, Literária, Biográfica e Bibliográfica, que circulou em Lisboa, Portugal, de outubro de 1894 a dezembro de 1896. Tendo o escritor e jornalista brasileiro Oscar Leal como diretor e F. Palmeirim como editor, o periódico priorizou, ao longo da sua existência, a publicação de material literário: poemas, crônicas, críticas, notas biográficas sobre escritores. A partir dessa produção, pretende-se lançar um olhar para os textos de autores brasileiros, entre os quais destacam-se os nomes de Machado de Assis e Olavo Bilac. Ao mesmo tempo, o foco do trabalho é ampliado, no momento em que também se examinam textos que, embora não estritamente literários, fazem alusão ao Brasil.

PALAVRAS-CHAVE: A Madrugada, Oscar Leal, relações Brasil-Portugal, periódicos literários, século XIX.

\section{THE PRESENCE OF BRAZIL AND ITS LITERATURE IN THE PORTUGUESE MAGAZINE A MADRUGADA (1894-1896)}

\begin{abstract}
This article has the objective to analyze some aspects of A Madrugada - A News, Critical, Literary, Biographical and Bibliographical Magazine that circulate in Lisbon, Portugal, from October 1894 to December 1896. The Brazilian writer and journalist Oscar Leal was the director and F. Palmeirim was the editor, and the periodic prioritized, during its existence, the publication of literary material: poems, chronicles, critics, biographic notes about writers. Since this production, we aim to take a look to texts from Brazilian authors, among which stand out Machado de Assis and Olavo Bilac. At the same time, the work focus of is enlarged, in the moment that texts are examined, although not strictly literary, allude to Brazil.
\end{abstract}

\footnotetext{
${ }^{1}$ Professor de Literatura do Instituto de Letras e Artes (ILA) da Universidade Federal do Rio Grande (FURG). Dr. em Letras (Teoria da Literatura) pela Pontifícia Universidade Católica do Rio Grande do Sul (PUCRS). Endereço eletrônico: mauropovoas@furg.br.

Jangada | nr. 16, jun/dez, 2020 | ISSN 2317-4722

107 | Pá g i n a
} 
KEYWORDS: A Madrugada, Oscar Leal, Relations Brazil-Portugal, literary periodicals, 19th century.

A Madrugada, especialmente destinada ao Brasil, será decerto apreciada pelo primor com que é redigida e pelo brilhantismo de

forma que reveste.

Da Verdade, de Tomar.

A epígrafe escolhida anuncia uma das principais características de A Madrugada, a de ser voltada para o Brasil, embora produzida em Lisboa. O excerto do jornal de Tomar foi retirado do penúltimo número do periódico aqui analisado, de setembro de 1896, em que são reproduzidos inúmeros trechos elogiosos da imprensa brasileira e portuguesa sobre $A$ Madrugada. E, realmente, chama a atenção, na revista, a presença acentuada de autores e obras brasileiros, elemento comentado a seguir.

A Madrugada - Revista Noticiosa, Crítica, Literária, Biográfica e Bibliográfica teve o seu primeiro número lançado no dia 28 de outubro de 1894, em Lisboa, capital de Portugal. Todas as edições perfaziam quatro páginas. Depreende-se que era, geralmente, mensal ou bimestral, embora haja irregularidades em sua periodicidade, como se pode ver na listagem dos quatorze exemplares disponíveis na Biblioteca Nacional de Portugal, distribuídos em quatro séries:

\section{Série I}

. ano 1, n. $1^{2}, 28$ out. 1894 ;

. ano 1, n. 2, 18 nov. 1894;

. ano 1, n. 3, 27 dez. 1894;

. ano 2, n. 4, 13 fev. 1895;

\section{Série II}

. ano 2, n. 5, 8 maio 1895;

. ano 2, n. 6, 27 jun. 1895;

. ano 2, n. 7, 4 ago. 1895;

. ano 2 , n. 8,18 set. 1895 ;

\section{Série III}

. ano 2, n. 9 , out. $1895^{3}$;

. ano 2, n. 10, dez. 1895;

\footnotetext{
${ }^{2}$ Em geral, a revista não apresentava numeração, mas para facilitar a identificação dos exemplares, enumeram-se, a seguir, as edições.

${ }^{3}$ A partir da terceira série, a revista não mais apresentou o dia da edição, somente o mês. 
. ano 3 , n. 11, jan. 1896;

. ano 3, n. 12, mar. 1896;

\section{Série IV}

. ano 3 , n. 13 , set. 1896 ;

. ano 3, n. 14, dez. 1896.

Os interesses de A Madrugada eram amplos, mas a literatura sobressaía-se, sendo o seu diretor o brasileiro Oscar Leal ${ }^{4}$; o editor (depois "Administrador") era F. Palmeirim, que permanece no cargo até o número de 4 de agosto de 1895. Alguns autores lusos importantes que assinam matérias ou poemas ao longo do periódico são Guiomar Torresão, Albertina Paraíso, Fialho de Almeida, Gomes Leal, Guerra Junqueiro, Bulhão Pato, entre outros, até para fazer cumprir a promessa do frontispício: "Redação composta dos melhores escritores portugueses", propaganda necessária num mercado, no século XIX, inflacionado por muitos jornais, revistas, almanaques que disputavam a atenção do público.

A correspondência deveria ser enviada para o número 222 do Correio Geral de Lisboa. A assinatura no Brasil, para o ano ou para a série inteira, era $10 \$ 000$ réis (fracos); seis meses ou meia série, $5 \$ 000$ réis, a ser pagos em notas ou em selos remetidos dentro de carta registrada ao diretor da folha. Para as ilhas e o Ultramar, o ano ou a série saíam por $1 \$ 500$ réis, e seis meses ou meia série, $\$ 800$ réis. Curiosamente, não apareciam os valores para Portugal continental. O primeiro editorial, assinado pela Direção, faz comentários sobre a empresa que ora se iniciava: as dificuldades inerentes, o destino incerto, a importância da imprensa na vida intelectual, a necessidade de uma imprensa livre. No fim do texto, um comentário explicita o porquê do nome A Madrugada: "O título desta folha recorda a hora tardia em que nas longas noites de insônia, deixamos a quentura fofa do leito para nos entregarmos ao estudo" (n. 1, p. 1). No cabeçalho, as letras, trabalhadas, sobrepõem-se a uma Lua envolta em nuvens, caracterizando uma noite:

\footnotetext{
${ }^{4}$ Oscar Leal nasceu no Brasil em 1862, mas sendo de família portuguesa, mudou-se, na infância, para a Ilha da Madeira. Além de escritor, jornalista e dentista, era um apaixonado por viagens, em especial pelas regiões Norte e Centro-Oeste do Brasil. A par o seu caráter viajante, fixa residência em Lisboa, onde falece em 1910. Francisco das Neves Alves tem uma série de sete livros sobre Oscar Leal, publicados em 2020 na Coleção Documentos (n. 29 a 35), editada pelo CLEPUL (Lisboa) e pela Biblioteca Rio-Grandense (Rio Grande). Os livros, que tratam especialmente das viagens de Leal, estão disponíveis no seguinte endereço: https://www.edicoesbibliotecariograndense.com/cole\%C3\%A7\%C3\%A3o-documentos. Acesso em: 28 out. 2020.
} 


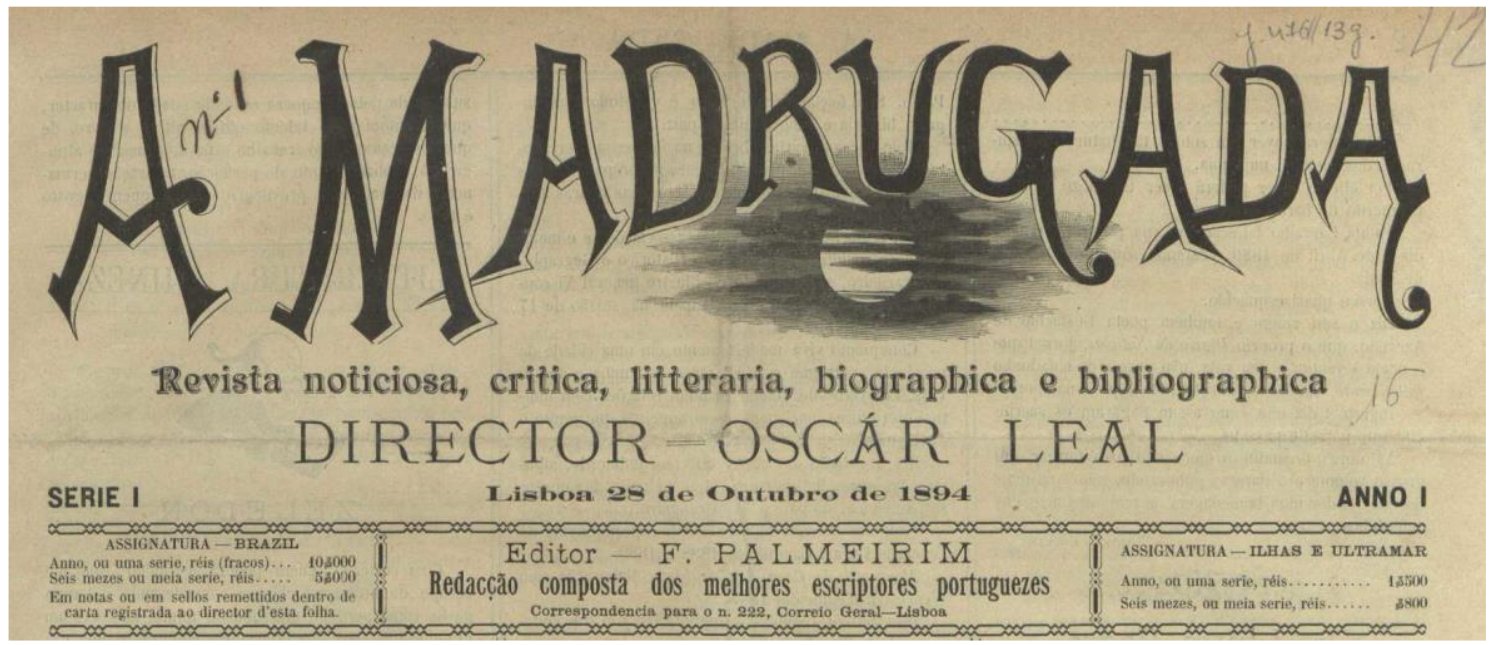

Alguns dados extraídos do primeiro número deixam clara a relação entre o Brasil e o periódico, explicitada, por exemplo, no "Expediente":

As pessoas residentes no Brasil que receberem o presente número da Madrugada, e desejarem continuar a receber os seguintes, para serem considerados assinantes, deverão remeter-nos em carta pelo correio, a quantia de dez mil réis (fracos), importância correspondente a uma série, um ano, ou cinco mil réis por meia série. A remessa pode ser feita em notas ou cédulas do tesouro ou em selos do correio (novos) do Brasil ou vale postal.

Esta empresa encarrega-se de biografias de pessoas notáveis e pede aos amigos do Brasil o seu valioso concurso, a fim de tornar-se cada vez mais interessante esta publicação, que continuará a ser ilustrada com gravuras de Pastor. (n. 1, p. 1)

O elo entre A Madrugada e o país sul-americano também aparece nas informações sobre os colaboradores:

Convidamos para nossos colaboradores-correspondentes no Brasil os Exmos. Srs.:

Estêvão de Mendonça - Mato Grosso.

Alberto Rodrigues - Rio Grande do Sul.

Artur Goulart, Carlos Ferreira, Lafaiete Toledo, Furtado Filho e Alberto Veiga - São Paulo. 
Luís Monteiro - Goiás.

Dr. Salazar Pessoa e Dr. Alberto Fleury - Minas.

Augusto Cardoso e João Barbosa - Rio de Janeiro.

Artur d'Albuquerque - Pernambuco.

Sérvulo Joaçaba e Dr. Aurélio Lavor - Ceará.

Luís Pinheiro e Dr. Oscar Galvão - Maranhão.

Cônego Ulisses Pennafort - Pará.

Dr. Benjamim Graça - Iquitos 5 . (n. 1, p. 1)

E, ainda, na indicação dos locais onde podia ser comprada a revista no Brasil:

Os primeiros números desta folha são encontrados à venda a 400 réis o exemplar:

Em Manaus - Na livraria: de Silva Gomes.

No Pará - Gomes \& Sousa.

Maranhão - Ramos d'Almeida \& Cia.

Ceará - Joaquim José d'Oliveira.

Pernambuco - Ramiro Costa \& Cia.

Maceió - Francino \& Filho

Bahia - Catilina \& Cia.

Rio de Janeiro - Lopes do Conto \& Cia., rua da Quitanda, 24.

Rio Grande do Sul - Carlos Pinto \& Cia.

Uberaba - Tobias Rosa.

Santos - A. Devesa \& Cia. (n. 1, p. 4)

A cada número, estampavam-se retratos de figuras públicas portuguesas e brasileiras, com destaque para os literatos. Na primeira edição, a ilustração é a de Antônio de Pádua Carvalho ("um dos poetas mais distintos e inspirados do Pará", n. 1, p. 1), acompanhado de um pequeno esboço biobibliográfico, como se tornará costume durante a vigência da revista. $\mathrm{O}$ texto fala da impiedosa crítica que Carvalho sofreu, para concluir que no Brasil há só zoilos ${ }^{6}$, sendo a verdadeira crítica feita somente por Tito Lívio de Castro, já falecido, e por Sílvio

\footnotetext{
${ }^{5}$ Embora listado entre os correspondentes no Brasil, Iquitos é uma cidade localizada na Amazônia peruana, relativamente próxima da fronteira com o Amazonas.

${ }^{6}$ Zoilo era o nome de um crítico grego do século IV a.C., bastante injusto e azedo com, especialmente, Homero. A palavra tornou-se sinônimo de mau crítico e difamador, sendo bastante comum no século XIX.
} 


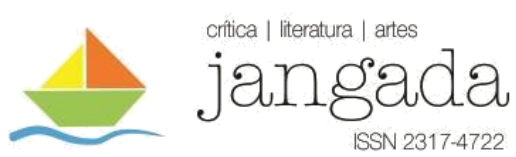

Romero, "crítico severo, mas justo" (n. 1, p. 1). Isso aponta para a incipiente cena literária brasileira, em que ataques, muitas vezes pessoais, dominavam os espíritos. E revela o interesse, em fins do século XIX, de tentar fazer a crítica literária ser levada a sério, como importante veículo de disseminação do conjunto de ideias de uma determinada literatura nacional ${ }^{7}$. Encerra o artigo a reprodução de um "mimoso soneto" de Pádua Carvalho, "Cromo", poema figurativo que mostra a dor de um pai e seu filho, com a morte da esposa e mãe.

Esse primeiro número já mostra como será o ordenamento desse tipo de matéria: o retrato do biografado, um pequeno texto dando conta de detalhes da vida e da obra do autor e a reprodução de um poema para ilustrar as suas qualidades literárias. São textos ora com autoria, ora assinados pela Direção. Destacam-se, nestas notas biográficas acompanhadas de retratos, escritores e pessoas relevantes da sociedade brasileira no final dos Oitocentos: Lauro Sodré (governador do Pará), Lafaiete de Toledo (escritor e guarda-livros), Ulisses Pennafort (padre), João Vieira da Silva (cônsul brasileiro em Portugal), Generoso Ponce (político, jornalista, comerciante e militar), Furtado Filho (escritor), Quintino Bocaiúva (jornalista e escritor), José do Patrocínio (jornalista), Afonso Celso Júnior (escritor e advogado), Clóvis Beviláqua (advogado), Aluísio Azevedo (escritor), Artur Azevedo (escritor), Tobias Rosa (jornalista), Revocata Heloísa de Melo (escritora e jornalista), Julieta de Melo Monteiro (escritora e jornalista), Horácio Nunes (dramaturgo), Sílvio Romero (crítico literário e professor), Raimundo Correia (poeta), Vítor A. Vieira (escritor; embora português de nascimento, vivia há muitos anos no Rio de Janeiro), Aderbal de Carvalho (escritor e advogado), Nelson de Sena (escritor e professor) e Artur Montenegro (escritor e historiador).

É uma lista heterogênea, com nomes de literatos conhecidos, como Sílvio Romero e os irmãos maranhenses Azevedo, mesclados a políticos, advogados, historiadores e padres. Como curiosidade, sobre Aluísio Azevedo é dito que

Hoje é considerado justamente como um dos mais distintos e festejados escritores brasileiros e irmão de outro igualmente distinto e bastante apreciado - Artur Azevedo.

\footnotetext{
${ }^{7}$ Neste sentido, o artigo "Crítica literária" (n. 10, p. 1), não assinado, comenta que um dos aspectos que mais impedem o "desenvolvimento de qualquer literatura é a falta de verdadeiros críticos", que não sejam "invejosos", "astuciosos" ou "maquiavélicos", para ficar em alguns dos termos usados no texto.
} 
Os seus livros, verdadeiros escrínios de beleza de estilo, são lidos com sofreguidão e poucos como ele, têm conquistado tantas e merecidas simpatias na sua pátria” (n. 11, p. 2).

Em edição posterior, é Artur Azevedo - dramaturgo, poeta, jornalista, ocupante de cargo público no Rio de Janeiro, onde vivia há muitos anos - que recebe um comentário elogioso: “É de todos os escritores brasileiros o que mais horas consome no trabalho mental" (n. 13, p. 1-2).

Há apenas duas mulheres neste grupo de brasileiros selecionados para saírem nas páginas da revista portuguesa. São elas as irmãs Revocata Heloísa de Melo e Julieta de Melo Monteiro, que tiveram atuação destacada na literatura do Rio Grande do Sul, desde o final do século XIX até meados do século XX, especialmente por meio do periódico Corimbo, que divulgou a literatura, na cidade do Rio Grande/RS, por várias décadas. No exemplar de março de 1896 (n. 12, p. 1), há os retratos das duas, acompanhados de notas que falam da vida e da carreira literária de cada uma delas, destacando os seus livros e as colaborações em jornais:

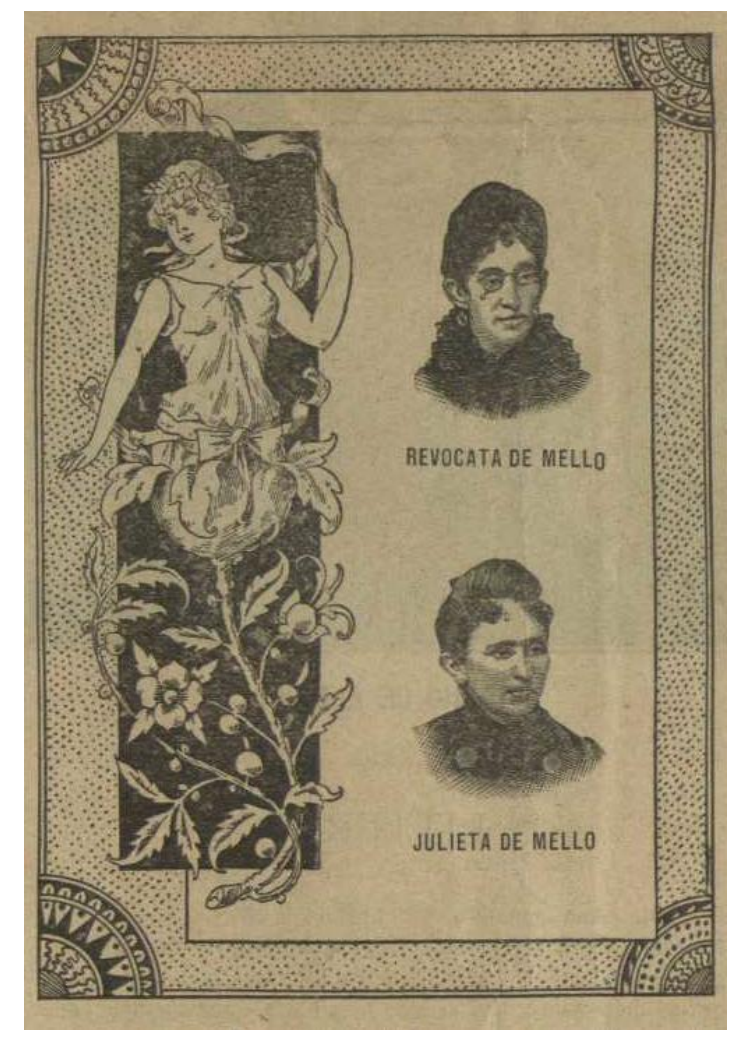

A divulgação da produção brasileira dava-se também pela reprodução de poemas de autores consagrados, ou não, como os que aparecem no número 5. Nessa edição, convivem autores canônicos, como Olavo Bilac, do Rio de Janeiro, com "Medalha antiga”, e outros pouco 
ou nada conhecidos, como Targela Barreito, de Pernambuco, com um soneto sem título, e Manuel Lobato, do Pará, com “A fantasia”. Abaixo, a reprodução do poema de Bilac (p. 2-3):
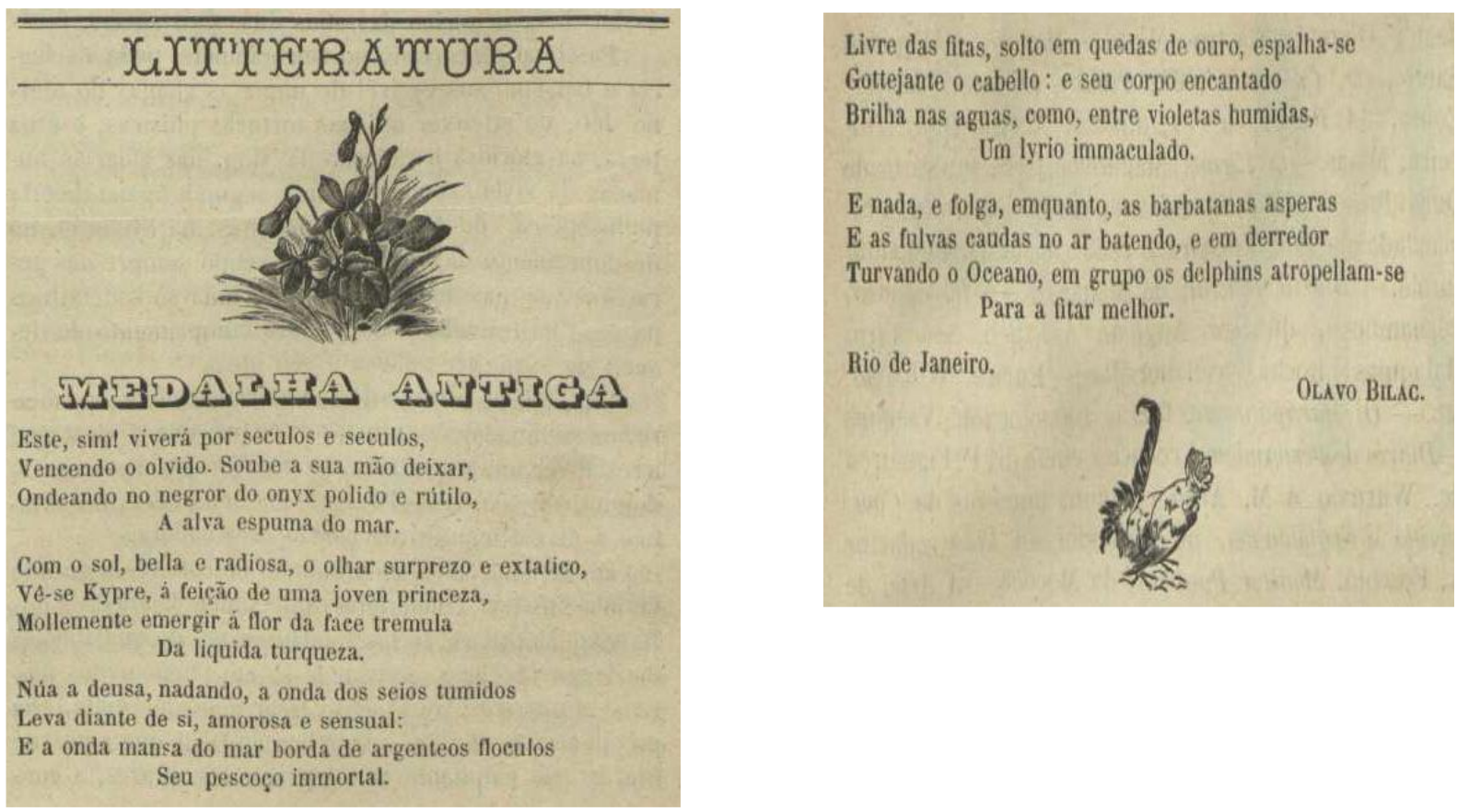

Outros escritores com reconhecimento na historiografia e na crítica literária brasileira, cujos poemas foram pulicados n'A Madrugada, são Raimundo Correia, Machado de Assis, Luís Guimarães Filho, Horácio Nunes e Aquiles Porto Alegre. Correia, maranhense, é um importante quadro do Parnasianismo, publicando na revista lisboeta "Plena nudez" (n. 6, p. 2; na revista, está sem título). Machado, que dispensa maiores comentários, apresenta-se com "A festa de Lindoia” (n. 11, p. 3), sem qualquer identificação se é brasileiro ou não, ou de qual estado origina-se, até porque, àquela altura, era já consagrado. Esse poema, que retoma a principal personagem feminina do poema épico Caramuru, de Santa Rita Durão, clássico do Arcadismo brasileiro, foi depois recolhido, somente como "Lindoia", na coletânea Ocidentais, de 1901: 


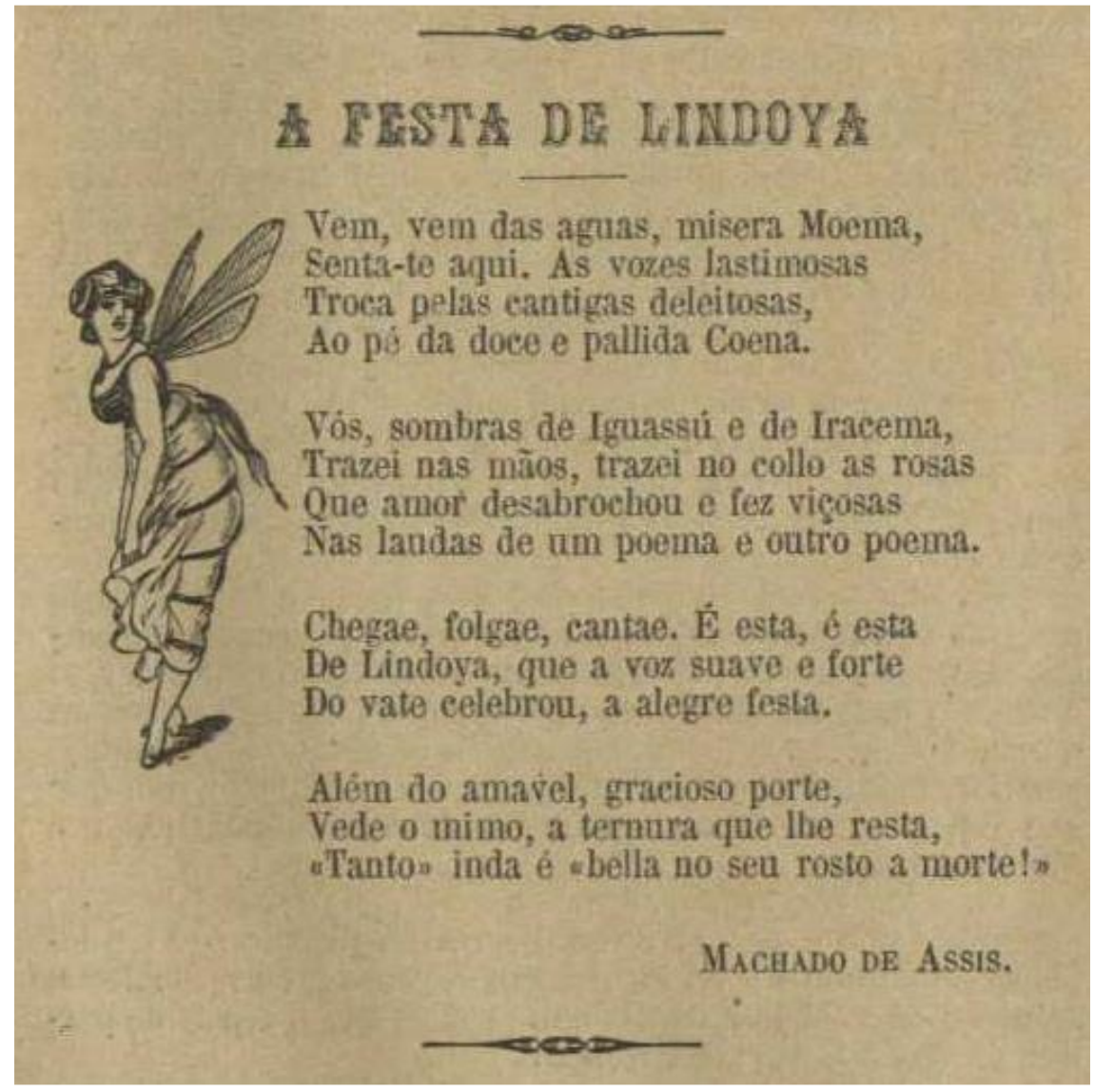

Poeta de feição parnasiana, o carioca Luís Guimarães Filho seguiu o pai, Luís Guimarães, nas carreiras literária e diplomática, sendo membro da Academia Brasileira de Letras desde 1917, ocupante da cadeira n. 24. Horácio Nunes nasceu no Rio de Janeiro, mas se mudou para Santa Catarina na infância. Servidor público, na literatura dedicou-se com mais afinco à escrita teatral. De Luís Guimarães, publicou-se o poema "O duelo" (n. 6, p. 2); de Nunes, "Haideia" (n. 10, p. 2) "Mar largo" (n. 12, p. 2) e "Visão" (n. 14, p. 3).

Aquiles Porto Alegre foi um autor importante na literatura sul-rio-grandense na virada do século XIX para o XX, em especial por seus diversos livros de crônicas e por sua participação (com poemas, contos e romances) na Sociedade Partenon Literário, de Porto Alegre, agremiação que editava a Revista Mensal (1869-1879), fundamental para a consolidação do Romantismo e do Regionalismo no Estado sulino. O soneto sem título (n. 9, p. 2), de temática amorosa, envolve um elemento comum na poesia brasileira, o mar, aqui retratado em seu movimento natural de apagar os indícios deixados pelo homem em sua areia, ação que não é o suficiente, porém, para fazer o eu-lírico esquecer a sua amada: 
Teu doee nome en eserevi, um dia,

$\mathrm{Na}$ fófa areia da deserta praia,

Onde a vaga soluça e o mar desmaia,

Onde a vaga chorava e 0 mar bramia.

Dias depois voltei $1 . . .0$ sol naseia

Lourejando a finissima cambraia,

Que a babugem do mar gemendo espraia

$\mathrm{Na}$ areia movediga, branea e fria.

Busquei teu nome em vão, por entre a espuma,

E nem uma só lettra, ao menos uma,

Eu encontrei eseripta sobre a areia.

Que importa $\ldots$... se o teu nome a cada instante,

Vibra alegre em meu peito palpitante,

Como a.voz d'um eanario que gorgeia.

Rio Grande do Sul.

Achylles Porto Alegre.

Chama a atenção o fato de, nas composições de A Madrugada, o poeta vir, em quase todos os casos, com a identificação de seu estado natal, até para que o leitor português mais facilmente organizasse as informações territoriais de um país tão grande, diversidade que a revista buscava dar conta ao publicar autores provenientes de todos os quadrantes, de Norte a Sul, do Pará ao Rio Grande do Sul.

Por outro lado, prova da seleção operada pelo tempo e pela crítica, vários são os poetas hoje desconhecidos que estampam as páginas de A Madrugada, às vezes até com duas ou mais composições, com a unidade de federação de origem, quando esta informação é disponibilizada, indicada entre parênteses: Cônego Ulisses Pennafort (PA), Euclides Dias (PA), Ernesto PaulaSantos (PE), Manuel Arão (PE), Rodrigues (CE), Martinho Rodrigues de Carvalho (CE), Guimarães Passos (RJ), Luís Pistarini (RJ), Lafaiete Silva (RJ), Lindolfo Gomes (MG), Venceslau de Queirós e Augusto Ribeiro. Cumpre dizer que vários desses escritores homenageiam o "bom amigo" Oscar Leal, responsável pela publicação, em dedicatórias ou títulos, fato comum no século XIX, em que o gênero lírico servia de canal para troca de favores, dando azo às chamadas "panelinhas literárias", que valorizavam o poema encomiástico ou a inscrição carinhosa. 
Um terceiro modo de A Madrugada divulgar o Brasil é por meio de pequenos textos críticos, que discutem tópicos específicos, como o artigo "Escritores brasileiros" (n. 6, p. 1), assinado pela Direção, que reclama da pouca divulgação da literatura brasileira em solo português, embora houvesse a dedicação de alguns, como Teixeira Bastos, de estreitar as relações literárias entre os dois países com laços identitários e linguísticos tão fortes. $\mathrm{Na}$ verdade, Bastos tinha acabado de lançar Poetas brasileiros, uma tentativa de retirar os escritores brasileiros do "cruel ostracismo" a que estavam entregues em Portugal, onde "são completamente desconhecidos muitos dos bons poetas e prosadores brasileiros, e é por isto que imparcialmente vamos sucessivamente apesentando alguns aos leitores portugueses". De certa forma, o artigo é a explicitação de uma das diretrizes do periódico, o de divulgar na Europa aqueles autores que Oscar Leal pensava ser de valia para tanto.

No mesmo diapasão é o texto "Literatura brasileira", na edição seguinte (n. 7, p. 1), também assinado pela Direção, em que avulta a discussão de que no Brasil, afinal, "existe e de fato uma literatura nacional". Todavia, há o lamento de que

Em Portugal só são conhecidas regularmente as obras de Gonçalves Dias, Castro Alves, Casimiro d'Abreu, José d'Alencar e de outros saudosos homens de letras do Brasil, ou de um ou outro da atualidade; mas lembrar, por exemplo, o lirismo social de Castro Alves, simplesmente, não significa mais do que assinalar ou descobrir apenas uma das raízes da árvore em que floresce a literatura brasileira.

Constata-se, a seguir, essa dificuldade de se encontrar em Portugal livros brasileiros, os quais, quando encontrados, são caros. Sobre esse assunto, o diretor conta a história de que “entrando na Livraria Chardron, hoje de Lello \& Irmão, no Porto", deparou-se com livros brasileiros e perguntou se essas obras tinham boa saída; a resposta foi desalentadora: "Que nem um exemplar existia vendido". O tex to termina com a seguinte assertiva, um corolário da revista lisboeta dirigida por Oscar Leal: "Queremos tornar conhecidos em Portugal os bons escritores brasileiros e havemos de fazê-lo como até aqui, sempre imparcialmente e sempre de comum acordo com a opinião dos nossos companheiros".

No mesmo número 7 (p. 4), há o artigo "O Pão do Ceará”, em que Lopes Carqueja, de Lisboa, critica veementemente Antônio de Sales, o editor do periódico cearense $O$ Pão - da agremiação literária Padaria Espiritual -, por suas críticas ao livro de Oscar Leal, Viagem a um país de selvagens. Carqueja quer alertar aos seus "confrades de além-mar acerca dos manejos Jangada | nr. 16, jun/dez, 2020 | ISSN 2317-4722 
e intenções do senhor Sales", que "não merece a menor atenção da parte deles. Antônio Sales é um desses zoilos do Norte do Brasil a quem devemos desprezar”.

No número 10 (p. 3), há um texto em que o título são os nomes de três escritores pernambucanos, “João Barreto, Manuel Arão, Ernesto Santos”, homenageados em texto e fotos, em especial por sua participação na Vanguarda, "simpática revista literária que se publica em Pernambuco". Outro texto interessante é "O escritor brasileiro" (n. 12, p. 2-3), assinado por V. M., em que é mostrado o quanto o autor do Brasil é mal remunerado, praticamente escrevendo de graça, em especial os principiantes e amadores. Já a coluna "Movimento literário", assinada por Oscar Leal, saída nos n. 11 e 12 (p. 3), respectivamente de janeiro e março de 1896, repassava notas rápidas sobre livros e autores brasileiros e portugueses.

Um quarto exemplo de material que faz referência ao Brasil são notícias gerais em torno do país sul-americano, como aquela sobre a imigração italiana, "Noticiário" (n. 7, p. 3), em que se contabilizam 760.000 italianos domiciliados e distribuídos por diferentes unidades da federação:

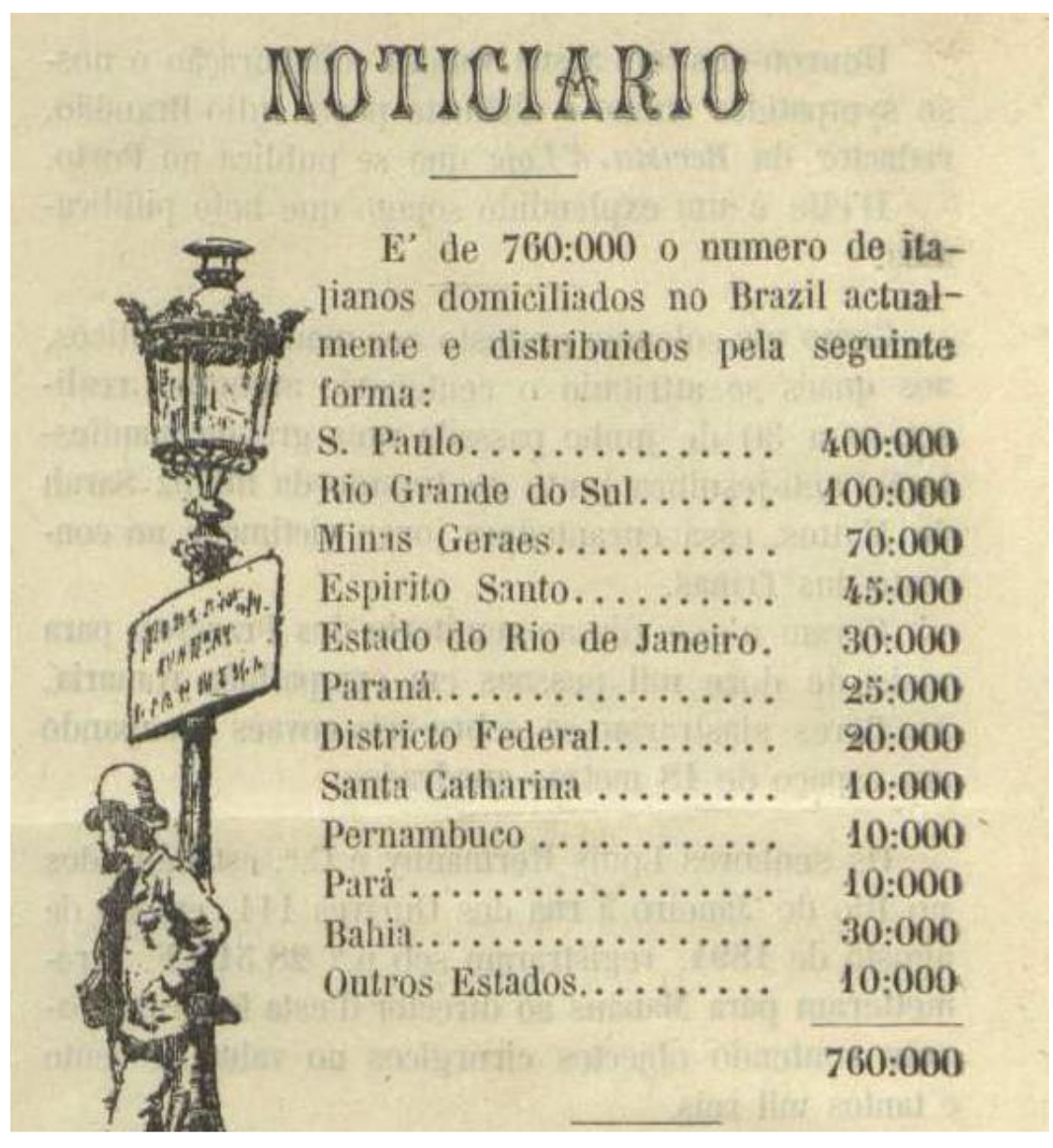


Um estado que, ao longo das edições de A Madrugada, tem uma presença constante é o Pará, até pelas viagens de Oscar Leal ao Norte do país. O território se faz presente seja em citações de escritores e figuras públicas, ou em alusões às suas cidades, como no artigo "O Pará”, assinado por Leal. (n. 9, p. 2-3). É a reprodução de uma conferência dele feita na Sociedade de Geografia de Lisboa, em 11 de novembro de 1894. Quando se fala em Pará, na verdade leia-se Belém, a capital, como no trecho abaixo:

\begin{abstract}
Não se parece com o Porto, nem com Lisboa, nem com Veneza, Nápoles ou qualquer outra capital europeia. O Pará é puramente, essencialmente, uma cidade americana, parecendo a certas horas do dia em que o calor equatorial aí se faz sentir com mais intensidade, entregar-se a delicioso espasmo, passadas as quais o movimento e o bulício se fazem sentir, denotando aos olhos do viajante extasiado, a grandeza do seu progresso sempre crescente e que aumenta ano a ano, dia a dia.
\end{abstract}

O texto traz vários elogios à cidade, sublinhando-lhe a beleza, as casas, a iluminação, e reforçando que "ninguém no Pará morre de fome, ninguém morre na via pública e nesta raras vezes se vê um pobre estender a mão para pedir uma esmola”. Ilustra o artigo uma gravura da bonita edificação da Bolsa do Pará:

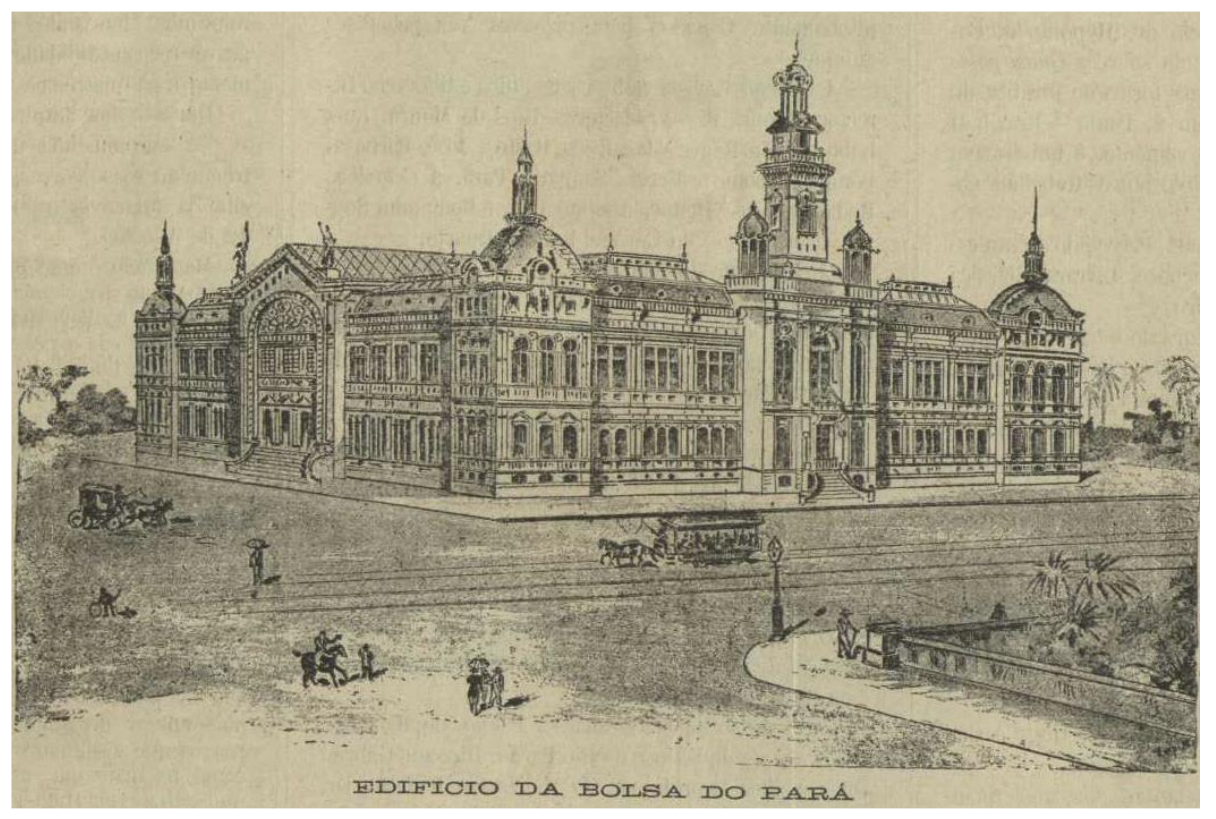




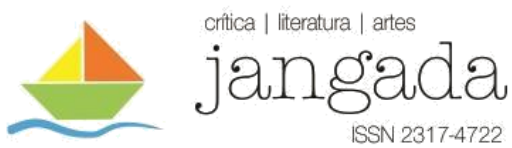

Também há notas como "A cidade do Rio de Janeiro" (n. 6, p. 4), que, apesar de pequena, vale a pena ser reproduzida, pelos dados geográficos e prediais interessantes e curiosos que carrega:

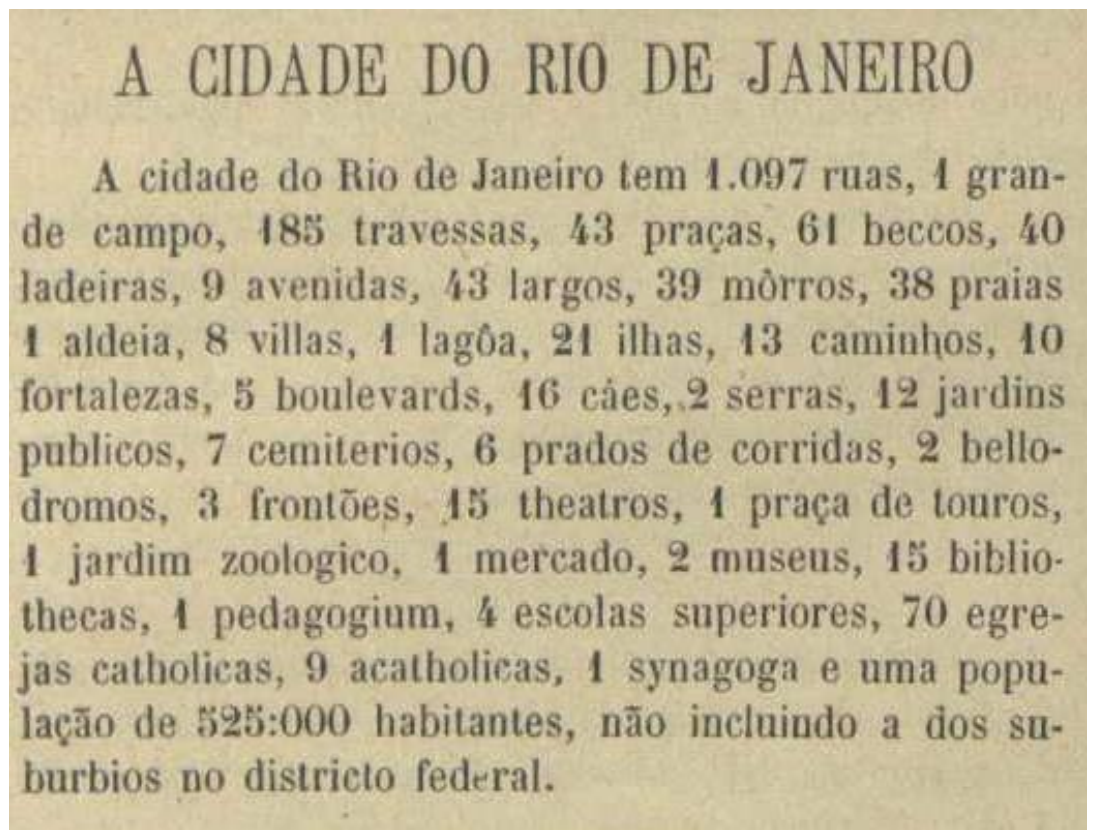

A análise de A Madrugada, por meio da reprodução de poemas, notas biográficas, artigos e notícias, mostra como se dava o diálogo entre Brasil e Portugal, que naquele momento se respeitavam mutuamente, como dois países independentes, embora com história e língua conjuntas, após uma longa e conturbada relação de colonizador e colonizado ${ }^{8}$. Algumas conclusões podem ser delineadas, a partir das considerações aqui exaradas:

1. a importância de divulgar (seja transcrevendo poemas, seja biografando) autores brasileiros, canônicos ou não, em Portugal, que pouco conhecia do que era publicado do outro lado do Atlântico, embora a língua em comum. A partir das publicações de A Madrugada, pode ser feito um pequeno cânone da literatura brasileira, com destaque para Olavo Bilac, Machado de Assis e Aluísio Azevedo, ao lado de uma série de escritores hoje pouco lembrados;

2. o destaque de vultos e personalidades brasileiros nos diferentes campos de ação social - na política, no direito, na literatura -, com ilustrações e dados biobibliográficos, numa visão

\footnotetext{
${ }^{8}$ Este exame sobre A Madrugada insere-se num conjunto de reflexões sobre as relações entre as literaturas brasileira e portuguesa no contexto do periodismo literário do século XIX, as quais foram objeto de meu pósdoutoramento na Universidade de Lisboa, em 2008, sob a supervisão do Prof. Dr. Ernesto Rodrigues. Alguns textos provenientes desta pesquisa estão listados nas referências.
} 
monumentalista que ressaltava a moralidade, a seriedade e outros atributos do caráter dos indivíduos escolhidos, e que, a princípio, no critério da revista, diferenciavam-se de seus pares;

3. a necessidade de reforçar que o Brasil já tinha uma literatura própria, mesmo no final século XIX, quase oitenta anos após a independência do país sul-americano;

4. a afirmação do fazer crítico, embora, no periódico em tela, na forma de pequenos textos, sem maior desenvolvimento analítico; nota-se o esforço de Oscar Leal em afirmar uma crítica mais "científica", distanciando-se da raiva característica dos supracitados zoilos e fugindo do impressionismo típico da época;

5. a publicização de dados sobre o Brasil, como o número de imigrantes italianos, importante pelo fato de haver escassez de fontes de acesso à informação no século XIX, sendo os periódicos decisivos no papel de levar notícia e dados estatísticos aos leitores, que, se não fosse por isso, não tomariam conhecimento do que ocorria pelo mundo.

\section{REFERÊNCIAS BIBLIOGRÁFICAS}

A Madrugada - Revista Noticiosa, Crítica, Literária, Biográfica e Bibliográfica. Lisboa, out. 1894/dez. 1896. Disponível em:

http://catalogo.bnportugal.pt/ipac20/ipac.jsp?session=G6039TS268578.145776\&profile=bn\& source $=\sim$ !bnp\&view=subscriptionsummary\&uri=full=3100024 $! 547968 \sim$ !8\&ri=1\&aspect=su btab11\&menu=search\&ipp=20\&spp=20\&staffonly=\&term=a+madrugada\&index=.GW\&uind ex=\&aspect=subtab11\&menu=search\&ri=1. Acesso em: 11 ago. 2020.

PÓVOAS, Mauro Nicola. A literatura brasileira em periódicos portugueses: textos críticos e notas biográficas. In: ; VAZ, Artur Emilio Alarcon (Org.). Literatura, história e fontes primárias. Curitiba: CRV, 2013. p. 201-215.

Fragmentos de história da literatura: relatos e resultados de uma pesquisa em Portugal. Letras de Hoje, Porto Alegre, v. 47, n. 4, p. 356-364, 2012.

Um projeto para dois mundos: as ilustrações luso-brasileiras. In: SIMÕES JUNIOR, Alvaro Santos; CAIRO, Luiz Roberto; RAPUCCI, Cleide Antonia (Org.). Intelectuais e imprensa: aspectos de uma complexa relação. São Paulo: Nankin, 2009. p. 53-75.

RAFAEL, Gina Guedes; SANTOS, Manuela (Coord.). Jornais e revistas portugueses do século XIX. Lisboa: Biblioteca Nacional, 1998-2002. 2 v. 